\title{
Political Efficacy of Emerging Elites in Post-Socialist Countries: The Impact of Disciplinary Culture and Political Opportunities
}

\author{
Valentina Dimitrova-Grajzl* \\ Eszter Simon ${ }^{\dagger}$ \\ Alex Fischer ${ }^{*}$
}

September 20, 2009

\begin{abstract}
Political efficacy is a key determinant of political participation, yet what are the determinants of political efficacy? While the role of demographic and socio-economic factors has been widely studied in this context, less attention has been given to early-life socialization and to the aggregate political environment. This paper develops and empirically tests the hypotheses that political efficacy of emerging elites in postSocialist countries is determined by (i) individuals' internalized values, which we proxy with the concept of 'disciplinary culture,' (ii) the structure of political opportunities, measured by the degree of a country's political competitiveness and openness, and (iii) the historical legacy of socialism. Our study contributes to a scarce literature on the topic of political efficacy in post-Socialist countries and to an even more scant literature on political efficacy of young people and emerging elites.
\end{abstract}

Keywords: Political efficacy, disciplinary culture, political opportunity structure, early life socialization, socialism, emerging elites

\footnotetext{
* (Corresponding author) Assistant Professor, Department of Public Policy, Central European University, Nador u. 9, Budapest 1051, Hungary, E-mail: dimitrova@ceu.hu, Phone: 001-540-460-8843

${ }^{\dagger}$ Visiting Professor, Euroatlantic Center, Economic University, Bratislava, Slovakia, E-mail: eszter_simon@yahoo.com

*Associate Professor, Central European University, DPP, Nador u. 9, Budapest 1051, Hungary, E-mail:

fischera@ceu.hu
} 


\section{Introduction}

In an age when emerging or young democracies struggle to involve citizens in the political process, it is essential to establish ways to promote political participation, and in particular participation of young people. Internal political efficacy, ${ }^{l}$ i.e. an individual's perception of whether (s)he can have an impact on the policy process, has been recognized as an important determinant of political participation (e.g. Seligson 1980; Cohen et al. 2001, Fox and Lawless 2005).

Given the importance of political efficacy for political participation and consequently for democracy, it is necessary to understand what factors influence it. Existing studies on political efficacy have researched extensively the role of individual-level characteristics such as gender, age, education (e.g. Karaman 2004, Wu 2003, Madsen 1978), political awareness (e.g. Karaman 2004, Pinkleton et al. 1998, Tewksbury et al. 2008, Langton \& Karns 1969), as well as country-specific factors such as the length of democratic experience of a country (Madsen 1978, Bowler and Donovan 2002). However, they have not effectively tackled two factors that seem important for political efficacy - internalized norms and the external political structure.

The aim of this paper, therefore, is to build upon the existing research on the determinants of political efficacy and analyze the role of internalized norms and the external political structure as determinants of political efficacy. We focus our study on young people, who represent the emerging elites of the post-socialist countries. It is particularly important to focus on young people and future elites in the context of the post-socialist countries because young people's political efficacy and political participation are crucial to ensure the long-term survival of democracy as well as the establishment of a strong democratic order in a region with little democratic history. Furthermore, countries' elites (political, social and economic) have an important contribution to establishing democratic values and conduct. This makes

\footnotetext{
${ }^{1}$ For the sake of brevity, we will refer to internal political efficacy as efficacy throughout the paper. It should be pointed out, however, that there is another concept of efficacy referred to as external political efficacy. External efficacy is defined as the individual's belief about the responsiveness of government (Karaman 2004, p. 32). We are interested in examining the determinants of individuals' self-perception rather than the determinants of individuals' perception of their environment. Therefore, this paper focuses solely on the issue of internal political efficacy.
} 
a study of the values of potential members of the future political elites useful (Stevens et al. 2006, pp. 607-608).

The paper puts forth two hypotheses. First, we argue that political efficacy is affected by both the historical and contemporaneous structure of political opportunities. The contemporaneous structure of political opportunities, which is an objective measure of a country's level of political competitiveness and openness, delineates the scope for an individual's political actions and thus shapes an individual's perception about the efficacy of his/her political actions. Furthermore, we argue that the historical legacy of little to no political opportunities under socialism has also had a profound effect on the present-day political efficacy of citizens of former socialist regimes.

Second, we argue that political efficacy is significantly influenced by internalized norms and values, more specifically by inclination to political activism - a product of early childhood socialization. We use a sample of graduate students at Central European University (CEU), which allows us to analyze the efficacy of young people, who are likely to become the future elites of the countries in CEE and fSU countries. In light of our sample, we draw on the concept of 'disciplinary culture,' developed by Windolf $(1992,1995)$ as a proxy for inclination to political activism. The term 'disciplinary culture' captures the motivation of students to study in general and to study a particular academic discipline.

The paper contributes to the existing literature in two ways. First, it analyzes factors, which have so far been under-researched or not researched at all, in studies on political efficacy. The paper provides empirical evidence for the significance of these factors. Our results illustrate that individual disposition to activism as well as the political opportunity structure play a key role in forming individuals' perception of the efficacy of their political actions. This suggests that factors both internal and external to an individual are important determinants of political efficacy.

Second, we contribute to a scarce literature on the efficacy of young people or elites (e.g. Stevens et al. 2006), as well as to the small number of studies, which research the determinants of political efficacy specifically in CEE or fSU (e.g. Anderson \& Tverdova 2001, Karaman 2004). 
The paper proceeds as follows. Section 2 puts forth our hypotheses on the determinants of political efficacy. Section 3 discusses the data. Section 4 presents the empirical results. Section 5 concludes.

\section{Political Efficacy, Political Opportunities and Individual Disposition}

We posit that two types of factors influence political efficacy: the opportunities the general political environment provides for political participation (historically as well as contemporaneously) and the disposition of the individual to react to the outside environment. Both arguments have been tackled indirectly by the literature. However, for the most part, the literature has offered neither a comprehensive analysis of these factors nor any empirical support for the hypothesis that these factors affect efficacy. We offer quantifiable proxies for both concepts; these proxies allow us to test empirically the effect of political opportunity structure and individual disposition on political efficacy. Furthermore, unlike the existing literature, we focus on young people, who are likely to become the elites in their countries of origin or in the international community.

\subsection{Structure of Political Opportunities}

We hypothesize that political efficacy of an individual is significantly affected by the "political opportunity structure" of the country, which the individual is a citizen of. ${ }^{2}$ The political opportunity structure of a country comprises of the "consistent ... dimensions of the political environment that provide incentives for people to undertake collective action by affecting their expectations for success or failure" (Tarrow 1994, p.85). Thus, our hypothesis states that the more situations there are for citizens to get involved in politics or the more open the political process is, the more likely citizens will feel efficacious.

To the best of our knowledge, the overall structure of political opportunities has not been explored as a potential determinant of political efficacy. Research on structural effects has focused on examining specific factors such as direct democracy and corruption. The closest argument to our claim 
that the overall political opportunity structure matters is that of Madsen (1978) who stipulates that the length of democratic experience has a significant effect on political efficacy. This variable, however, becomes irrelevant when studying countries in the CEE and fSU regions, since it displays little to no variation.

Aside from the contemporaneous structure of political opportunities, historical legacies also matter. The socialist legacy of few to no political opportunities has had a profound effect on the societies of post-socialist states. Socialism instilled in citizens a submissive attitude toward authority, lack of individualism, and support for collectivism. We expect such attitudes to persist in post-socialist societies. Consequently, decades of socialism managed to establish a profound lack of confidence that any action and more so any individual political action could have an effect on the political, economic or social reality. Our second hypothesis, therefore, states that people from former socialist countries feel less efficacious than people from non-socialist countries.

\subsection{Individual Disposition}

With regard to the individual's disposition to react to the outside environment, two factors are important. First, some researchers (e.g. Langton and Karns 1969) have suggested that early life socialization is an important determinant of efficacy. We take this suggestion a step further by providing a quantitative measure that captures one specific outcome of socialization - internalized values and more specifically individual's inclination to political activism. Because of early life socialization, individuals internalize norms and attitudes, and develop a particular disposition toward the world in general.

Individuals, who have learned that they should lead rather than follow and, thus, have a high inclination to activism, are likely to feel more efficacious than individuals with low inclination to activism.

Furthermore, individuals who have learned to pursue their ambitions are likely to take action, to seek office and further their careers. Individuals who have been taught to strive to improve the well-being of others are likely to seek occupations that help them create change in the world or in their own lives.

\footnotetext{
${ }^{2}$ The term "political opportunity structure" was first used by Eisinger (1973) and since then has become a key concept in the social movement literature and, in particular, in protest studies (e.g. McAdam et al. 1996, Kriesi
} 
To proxy for an individual's internalized values, in light of our sample specifics, i.e. graduate students at an international university, we use the concept of "disciplinary culture, ${ }^{3}$ which captures the culture that a particular academic discipline represents. Disciplinary culture accounts for internalized values because "students seek out to integrate themselves into a disciplinary culture which offers them the same sorts of values and norms, which they have already internalized, and the natural affinity between the two leads to a self-selection on the part of the students confronting the question of what subject to choose" (Windolf 1995, p. 211). In other words, students self-select themselves into disciplinary cultures that are aligned with their internalized values.

In line with the approach of Windolf $(1992,1995)$, Armingeon et al. (2000), and Armingeon (2001), we differentiate between four dimensions of disciplinary culture. The first dimension is career orientation. This dimension captures the values of a performance-oriented society and puts positive value on the ethos of a professional career. More specifically, a student who is studying to enhance their career opportunities, to create more employment and earning possibilities for themselves in the future would score high on this dimension. The second dimension, reform-orientation, captures the inclination of an individual to help, change and reform. In other words, students who are studying because they believe they can learn about societal problems and help reform the existing order would score high on this dimension. The third and fourth dimensions - lifestyle and science orientations - are not instrumental for our purposes, but are briefly discussed here since they help us distinguish the first two dimensions. People who are lifestyle oriented are studying as a means to gain time before embarking on a professional life and hence use studying as a deferment to the responsibilities of post-student life. People who score high on the science dimension have a genuine interest in scientific research and methods as such instead of treating them as a means to an end (as, for example, career-oriented students do).

Career orientation suggests that an individual is proactive about finding new opportunities, creating possibilities for employment, and believing that his/her actions will lead to a better outcome.

1995).

${ }^{3}$ The term was put forth and developed by Windolf $(1992,1995)$. 
Career orientation, therefore, implies a belief that one's own actions can bring about change in one's social status, employment and earning potential. We, therefore, expect that career orientation translates into a higher degree of efficacy in every area of life, including politics.

In addition, reform-oriented students have a high level of political efficacy, because they not only have an activist disposition, but their goals are directed toward the main aim of political action: bringing change. In other words, values, fostering activism in one area of life, will result in a general sense of efficacy, which pertains to all areas of life including politics.

With regard to the second individual disposition factor, we follow Karaman (2004, p. 36) who suggests that political awareness plays a key role in determining political efficacy. More specifically, the more interest an individual has in politics, the more likely it is that they feel their individual actions can make a difference. The chain of causation is similar to the logic of why interest in math leads to perception of higher efficacy in math. If we are interested in math, we are likely to be aware of a wide range of mathematical concepts and rules. This knowledge, in turn, will provide the necessary tools for solving math problems and will make it worthwhile for us to engage in the task of solving problems. Furthermore, the access to more mathematical tools will likely increase our perception of how successful we will be in solving a given mathematical problem. Applying this logic to political interest, we expect that more interest in politics will lead to more knowledge and more knowledge will lead to stronger interest, which in turn will lead to a higher degree of efficacy. As a proxy for awareness, we use 'interest in politics' and 'importance of politics in one's life', which are closely correlated with awareness and knowledge of political issues.

\subsection{Hypotheses on the Determinants of Political Efficacy of Emerging Elites}

In sum, we put forth the following hypotheses:

H1: A more open political opportunity structure leads to higher political efficacy.

H2: Individuals from former socialist countries have lower political efficacy than individuals from nonsocialist countries.

H3: More reform-oriented individuals have higher political efficacy than less reform-oriented individuals. 
H4: More career-oriented individuals have higher political efficacy than less career-oriented individuals.

H5: Higher political awareness leads to higher level of political efficacy.

\subsection{Other determinants}

Education has been recognized as a key demographic factor affecting political efficacy (e.g. Wu 2003, Bowler and Donovan 2002). However, due to the lack of variation in educational attainment of participants in the survey, we do not include education as an explanatory variable in our model. This, in fact, allows us to analyze in depth other factors, which given a certain level of educational attainment, help explain variation in political efficacy.

Some studies (e.g. Bowler and Donovan 2002; Wu 2003, Karaman 2004) have found a significant effect of other demographic factors, such as gender, age and socioeconomic status on efficacy. Given the focus of our paper and the specificities of our sample - graduate students - we do not expect age and socioeconomic status to play a significant role. We include age and gender in our studies, but exclude socioeconomic status since the majority of students at CEU are recipients of university scholarships (covering both tuition and living expenses), which are relatively uniform and do not provide enough variation in students' present socioeconomic situation.

\section{Data}

\subsection{Data Sources}

Our main source of data is an institutional survey of students at Central European University, an international graduate university with students from over 100 countries, where more than $60 \%$ of the students come from Central and Eastern Europe (CEE) and the former Soviet Union (fSU). The Survey targeted the 2006/2007 student cohort at CEU and was administered primarily in the form of a written questionnaire $^{4}$ in April and May 2007. The overall response rate was 59\%.

Although existing surveys, such as the World Value Survey and the European Social Survey, have a much richer pool of data on values and attitudes, they are not well suited for studies of young people who are likely to become members of the social, economic, and political elites of CEE states. To 
identify individuals who are likely to represent emerging elites, it is important to know their age, educational attainment, future ambition to pursue a career in business, politics, or academia, as well as career placements of students at the university they are attending. Most existing surveys do not differentiate between undergraduate and graduate education even though this is an important distinction in gauging the pool of feasible career paths of young people - for instance, nowadays, a master's degree is a requirement for most job openings in academia, business, and politics; hence people with bachelor's degrees are unlikely to be considered for such jobs. Moreover, none of the existing surveys contain data that could allow us to draw specific conclusions about the likely future careers of respondents.

As opposed to this and in accordance with CEU's mission "to become a change maker in the region [CEE and fSU] and beyond, with a special focus on contemporary challenges of open society, and democratization, ${ }^{5}$ the majority of CEU students tend to return to their home countries and to become active members of the political, economic and social elite of their countries. The students from the 2006/2007 CEU cohort - our target population - are well-placed to reach highly influential jobs in the future: for example, some of them have found employment in the Bulgarian Council of Ministers, The Georgian Ministry of Environmental Protection and Natural Resources, The Slovak Ministry of Foreign Affairs, the Policy Association for an Open Society in the Czech Republic, or the Romanian Institute for Public Policy and the European Environmental Bureau.

On a more general level, since the founding of the university 18 years ago, a number of CEU graduates have already secured highly influential government positions: to name a few, an Estonian Minister of Education; two ministers of Justice (in Romania and Georgia), an Assistant Minister, Ministry for European Integration of Croatia; and a Secretary, Council for Regulatory Reform at the Government of the Republic of Serbia. ${ }^{6}$

Building upon entry, exit and mid-year academic surveys at British and American universities, two West-European surveys carried out by Windolf (1992) and Armingeon et al. (2000) respectively, and

\footnotetext{
${ }^{4}$ Confidentiality of answers was ensured for all participants.

${ }^{5}$ www.ceu.hu (mission)
} 
the World Value Survey, our survey questionnaire comprises of questions on attitudes, values, past experience as well as personal characteristics of students. We also use data from the Polity IV database and from Freedom House. Table 1 presents all variables used in the empirical analysis and provides summary statistics.

\subsection{Measure of Political Efficacy}

Our measure of the dependent variable - political efficacy (PE) - is an aggregated index of opinions on efficacy of nine political activities. We rely on the following question, borrowed from Armingeon et al. (2000) $)^{7}$ : There are diverging opinions on how one can effectively influence society. Based on your experience in your home country, indicate how effective you think it is to: (1) work for a political party, (2) participate in an association, (3) participate in elections, (4) contact politicians personally, (5) try to catch the attention of the media, (6) boycott certain products, (7) participate in demonstrations, (8) participate in illegal protest activities, (9) participate in referenda." The nine efficacy variables range from 0 (not at all effective) to 10 (very effective). The aggregated index of political efficacy - summation of scores for all types of efficacy - ranges from 0 to 90.

\subsection{Individual Disposition}

We use two variables to capture individual disposition to activism - disciplinary culture and political awareness. In our operationalization of disciplinary culture, we follow Windolf $(1992,1995)$, Armingeon et al. (2000) and Armingeon (2001). Accordingly, students were asked to answer a series of questions on their motivation (1) to pursue graduate studies and (2) to choose a particular discipline. In line with the above-mentioned authors, we use a principal component factor analysis with varimax rotation and a fixed number of four factors - career, lifestyle, science, and reform. ${ }^{8}$ Similarly to Armingeon et al. (2000), we eliminate the statements, which do not load with at least 0.4 on at least one factor. Following this rule, one item is removed from the list ("I want to be well prepared to take over the

\footnotetext{
${ }^{6}$ http://online.ceu.hu/alumni_placement.html

${ }^{7}$ Translated from German to English by one of the authors of this article.

${ }^{8}$ The loadings of the original statements onto the four factors are available upon request from the authors.
} 
family business"). ${ }^{9}$ Unlike Armingeon et al. (2000), we use both statements related to the general motivation to pursue graduate studies and more specific statements related to the choice of a specific discipline.

As a robustness check (given the limitations of principal component analysis), we use individual survey statements on disciplinary culture, which load most significantly onto the reform and career factors. As proxy for reform orientation, we use the importance rating of the statements "I am studying because I would like to contribute to societal change". As proxy for career orientation we use the question "How important was the expected income in your future profession in your choice of academic discipline."

As a proxy for political awareness, we use the variable "interest in politics" or "importance of politics". ${ }^{10}$ The 'importance of politics' variable ranges from 0 (not all important) to 10 (very important) The 'interest in politics' variable ranges from 0 (not all interested) to 10 (very interested).

\subsection{Political Opportunity Structure}

We use the Polity variable from the Polity IV database to determine the structural constraints potentially affecting efficacy. The Polity variable (Marshall and Jaggers 2002) ranges from -10 (least open) to 10 (most open). As a robustness check, we use Freedom House data on political rights and civil liberties. The Freedom House indicators range from 1 (highest level of freedom) to 7 (lowest level of freedom). We take the average of the years 2002, 2003, and 2004 for both variables.

We also explore the role of the historical legacy of socialism. To measure the impact of the socialist legacy on political efficacy, we create a dummy variable, which assigns value 1 if a country was under socialism during the period $1950-1989$ and 0 otherwise. ${ }^{11}$

\footnotetext{
${ }^{9}$ The loading of factors was quite similar to Armingeon et al. (2000) and Armingeon (2001) in a study of Swiss college students.

${ }^{10}$ Both of these variables - 'interest in politics' and 'importance of politics' - have been used with similar wording in the European Social Survey, available at http://qb.soc.surrey.ac.uk/surveys/ess/main_questionnaire02.pdf (pages 7 and 35)

${ }^{11}$ Some papers (e.g. Karaman 2004, Letki 2004) have suggested that membership in the Communist party during socialist times has had an effect on efficacy or participation. Membership in the Communist party is firstly not a relevant proxy for our sample since most students at CEU are too young to have been able to join the party as adults prior to 1989. Second, we believe that membership in the Communist party might not be an appropriate proxy for
} 


\section{Main Findings}

In this section, we present our regressions on the determinants of political efficacy. Tables 2 and 3 summarize our OLS results. All regressions include the main explanatory variables - political opportunity structure, measures of internal norms and a measure of political awareness - that we put forth in Section 2 as determinants of political efficacy. However, to test the robustness of our results, we use at least two different measures for each of these explanatory variables. All regressions include age and gender as control variables.

Columns 1-4 of Table 2 use the factors from the principal component analysis as proxies for disciplinary culture. We find that individuals who are more policy and career oriented (in terms of their disciplinary cultures) have a higher sense of efficacy. Both variables enter the regression positively and significantly at the 5\% level. This provides support for Hypotheses 3 and 4, as stipulated in Section 2. Career oriented students, through their professional ambition, tend to have an active disposition and as expected have higher level of political efficacy. Reform oriented students have an active disposition toward life and, moreover, direct their activism toward politically motivated behavior, which in turn leads to a higher sense of political efficacy. Lifestyle and science disciplinary cultures enter positively but insignificantly in the regression.

As a robustness check, we also run the regression using individual statements on disciplinary culture (see Section 3.3. for details) as proxies for reform orientation and career orientation. Column 5 of Table 2 report the results. Our findings with the alternative specification support our initial results that the more reform-oriented or career-oriented a student is, the more efficacious, (s)he feels.

The importance of motivation to engage in politics is further substantiated by the positive, statistically significant coefficient of 'political awareness' variable. We use two different variables to measure political awareness - 'interest in politics' and 'importance of politics' in one's life. There is a 
relatively strong positive correlation between these two proxies of awareness, which indicates that people who have a strong interest in politics also find politics to be an important factor in their lives. Columns 1 of Table 2 reports results with the 'interest in politics' variable, while Columns 2-5 use the 'importance of politics' variable as a proxy for political awareness. In all cases, we find a positive and significant at the $1 \%$ level effect of political awareness on political efficacy, which confirms the earlier findings of Karaman (2004) and Amnå et al. (2004). Thus, we find support in favor of Hypothesis 5.

Results with regard to behavioral disposition and interest in politics/importance of politics suggest that the individual's feeling of efficacy is partly internally determined. On the other hand, we find that political opportunity structure also has a significant positive effect on the perception of overall political efficacy (Hypothesis 1). Columns 1, 2, and 5 of Table 2 present the results using the Polity variable, while Columns 3 and 4 provide robustness checks by using a different data source - Freedom House data on political rights and civil liberties. In all cases, we find a significant (at the $1 \%$ level) effect of the structure of political opportunities on political efficacy. Polity has a positive effect on political efficacy, while political rights and civil freedoms have a negative effect (recall the Freedom House variable scales indicate more rights with lower score and fewer rights with higher score). This result could suggest that given citizens' behavioral dispositions, government action, by opening up citizens' access to the political process, can influence the sense of political efficacy of citizens.

Table 3 presents our OLS results on various regressions, which test the effect of the socialist past along with the main variables utilized in Table $2 .{ }^{12}$ The inclusion of the Polity variable along with the socialist dummy does not change the sign and significance of the socialist variable. This suggests that even when we control for the current status of political opportunities, the socialist legacy plays a significant role in determining political efficacy. In both cases, with and without the Polity variable, there is a negative and statistically significant at the $1 \%$ level effect of the socialist legacy on political efficacy

\footnotetext{
${ }^{12}$ We run but do not report robustness checks of historical legacy, using various measures of the length of democratic experience. The tests show that the length of democratic experience loses its significance once the polity variable is included.
} 
(Hypothesis 2). The order, which existed to varying degrees in all socialist countries, precluded the possibility for free assembly, free speech, political participation or any citizens' input in governing. Furthermore, the socialist doctrine instilled in citizens a sense of obedience and conformity. This, in turn, translated into little or no sense of political efficacy, and in fact little initiative for change.

Our control variables, age and gender, do not have a significant effect on political efficacy. This is expected due to the specificity of our sample.

\section{Conclusion}

This paper shows that on the one hand, political efficacy is strongly influenced by factors that are internal to the individual such as interest in politics and disciplinary culture. On the other hand, the opportunities that the contemporaneous political system provides for its citizens to participate in the political process and the socialist experience of conformity, collectivization and suppression are strong external determinants of political efficacy. Admittedly, there were significant differences among the former socialist regimes of $\mathrm{CEE}$ and $\mathrm{fSU}$ countries, which could explain further variation in political efficacy. It is beyond the scope of this paper to analyze variation in efficacy based on type of socialist regime. However, future research should seek to incorporate the legacies of different types of socialism on political efficacy.

The significance of structural factors and the negative influence of the socialist legacy suggest that governments have a crucial role to play in fostering political efficacy. To begin with, it is vital for governments to show to their citizens that democracy differs from the former socialist systems in that it allows for meaningful public deliberation and for the involvement of citizens in the political process. Thus, post-socialist countries need to improve their institutional structure, allowing their citizens greater access to politics and promoting the competitiveness and openness of the political processes. Among other things, this would necessitate the establishment of a strong, independent, and financially viable civil society, which has been shown to aid the deliberative democratic processes (Grajzl \& Murrell 2009).

The defining role that personality traits and behavioral disposition play in determining political efficacy suggests that policymakers should focus on improving early childhood education so that to foster 
confidence and efficacy in children, who are likely to then grow up to be competent, politically active and efficacious adults. For example, authoritative teaching techniques prevalent in CEE and fSU, such as frontal lecturing, which put students into a passive role throughout their education (Rado 2001, p. 62; OECD 2003, pp. 90 and 367) should change in favor of a teaching philosophy that makes it possible for young people to take a more active role in their learning and, indirectly, in matters concerning them. Compulsory civic education, including school elections and mock legislative sessions, could also help foster activism and enhance interest and knowledge of politics which we also find to be positively correlated with political efficacy.

In order to reinforce our findings in a broader context, future work should seek to incorporate a more representative survey of elites or the general population of the former socialist countries.

\section{References}

Amnå, Erik, Ingrid Munch, Pär Zetterberg. 2004. "Meaningful Participation? Political Efficacy of Adolescents in 24 Countries." Paper presented at the Emerging Repertoires of Political Action: Toward a Systemic Study of Post-Conventional Forms of Participation at ECPR Joint Sessions of Workshops, Uppsala.

Anderson, Christopher J. and Yuliya V. Tverdova. 2001. "Winners, Losers, and Attitudes about Government in Contemporary Democracies." International Political Science Review 22(4): 321-338. Armingeon, Klaus, Michelle Beyer and Alex Fischer. 2000. "Studierende und Politik. Eine Befragung der Studierenden der Universität Bern." Bern.

Armingeon, Klaus. 2001." Fachkulturen, soziale Lage und politische Einstellungen der Studierenden der Universität Bern." (unpublished manuscript).

Bowler, Shaun and Todd Donovan. 2002. "Democracy, Institutions, and Attitudes about Citizen Influence on Government." British Journal of Political Science 32 (2): 371-390. 
Cohen, Aaron, Eran Vigoda and Aliza Samorly 2001. "Analysis of the Mediating Effect of PersonalPsychological Variables on the Relationship between Socioeconomic Status and Political Participation: A Structural Equation Framework." Political Psychology 22 (4) : 727-757.

Eisinger, Peter K. 1973. "The Conditions of Protest Behavior in American Cities." American Political Science Review 67: 11-28.

European Social Survey. Available at: http://qb.soc.surrey.ac.uk/surveys/ess/main_questionnaire02.pdf. Last accessed in March 2009.

Fox, Richard L. and Jennifer L. Lawless. 2005. "To Run or Not To Run For Office: Explaining Nascent Political Ambition." American Journal of Political Science 49 (3): 642-659.

Freedom House, www.freedomhouse.org

Grajzl, Peter, and Peter Murrell. 2009. "Fostering Civil Society: Why and When." Economics of Transition 19 (1): 1-41

Karaman, Tatyana. 2004. "Political Efficacy and Its Antecedents in Russia." Journal of Communist Studies and Transition Politics 20 (2): 30-49.

Kriesi, Hanspeter. 1995. "The Political Opportunity Structure of New Social Movements." In J. Craig Jenkins and Bert Klandermans Eds. The Politics of Social Protest: Comparative Perspectives on States and Social Movements. Minneapolis: University of Minnesota Press.

Langton, Kenneth P. and David A Karns. 1969. "The Relative Influence of the Family, Peer Group, and School in the Development of Political Efficacy." Western Political Quarterly 22 (4): 913-826.

Letki, Natalia. 2004. "Socialization for Participation? Trust, membership and Democratization in EastCentral Europe." Political Research Quarterly 57 (4): 665-79.

McAdam, Doug, John D. McCarthy, Mayer N. Zald. 1996. "Introduction: Opportunities, mobilizing structures, and framing processes - towards a synthetic, comparative perspective on social movements." In Doug McAdam, John D. McCarthy, and Mayer N. Zald. Eds. Comparative Perspectives on Social Movements. Cambridge, NY: Cambridge University Press. 
Madsen, Douglas. 1978. "A Structural Approach to the Explanation of Political Efficacy." American Journal of Political Science 22 (4): 867-883.

Marshall, Monty G and Keith Jaggers. 2002. "Polity IV Project: Users' Manual." Available: www.cidcm.umd.edu/inscr/polity. Last Accessed on October 15, 2008.

OECD. 2003. Reviews of National Policies for Education: South Eastern Europe. Vol. 2: FYROM, Moldova, Montenegro, Romania, Serbia. OECD Publishing.

Pinkleton, Bruce E, Erica Weintraub Austin, and Kristine K. J. Fortman. 1998. "Relationship of Media Use and Political Disaffection to Political Efficacy and Voting Behavior." Journal of Broadcasting and Electronic Media 42(1): 34-50.

Rado, Peter. 2001. "Transition in Education: Policy Making and the Key Educational Policy Areas in the Central-European and Baltic Countries." Open Society Institute, Education Support Program Paper \# ED457308. Available at: http://www.osi.hu/iep/papers/transit.pdf. Last accessed on December 18, 2008

Seligson, Mitchell A. 1980. "Trust, Efficacy and Modes of Participation: A Study of Costa-Rican Peasants." British Journal of Political Science 10 (1): 75-98.

Stevens, Daniel, Benjamin G. Bishin, and Robert R. Barr. 2006. "Authoritarian Attitudes, Democracy, and Policy Preferences among Latin American Elites." American Journal of Political Science 50 (3): 606-620.

Tarrow, Sidney. 1994. Power in Movement: Social Movements, Collective action and Politics. Cambridge: Cambridge University Press.

Tewksbury, David, Michelle L. Hals, and Allyson Bibart. 2008. "The Efficacy of New Broadcasting: The Relationship of News Consumption Style and Social and Political Efficacy." Journalism and Mass Communication Quarterly 84 (2): 257-272.

Titma, Mikk, Liina Mai Tooding, and Nancy Brandon Tuma. 2004. "Communist Party Members: Incentives and Gains." International Journal of Sociology 34 (2): 72-99 
Windolf, Paul, 1995. "Selection and Self-Selection at German Mass Universities." Oxford Review of

Education. 21 (2): 207-231.

Windolf, Paul. 1992. "Fachkultur und Studienfachwahl. Ergebnisse einer Befragung von

Studienanfängern." Kölner Zeitschrift für Soziologie und Sozialpsychologie 55(1): 76-98.

World Value Survey. Available at: http://www.worldvaluessurvey.org/. Last Accessed on December 14, 2008 .

Wu, Chung-Li. 2003. "Psycho-Political Correlates of Political Efficacy: The Case of the 1994 New Orleans Mayoral Election." Journal of Black Studies 33 (6): 729-760.

\section{Acknowledgements}

The authors would like to thank Rositsa Bateson and Anca Simionca for their help in implementing the CEU survey. We would also like to thank Peter Grajzl and Gabor Toka for valuable comments.

Table 1: Descriptive Statistics

\begin{tabular}{|c|c|c|c|c|c|c|}
\hline Variable & Source & Obs. & Mean & St. Dev & \multicolumn{2}{|c|}{ Max } \\
\hline Gender (1- male, 2 - female) & Survey & 445 & 1.503 & .5006 & 1 & 2 \\
\hline Age & Survey & 434 & 26.921 & 3.817 & 21 & 46 \\
\hline Political Opportunity Structure & Polity IV database & 432 & 7.251 & 4.420 & -9 & 10 \\
\hline Civil Liberties & Freedom House & 437 & 2.426 & 1.425 & 1 & 7 \\
\hline Political Rights & Freedom House & 437 & 2.423 & 1.425 & 1 & 7 \\
\hline Socialism & Authors' construct & 437 & .7208 & .4491 & 0 & 1 \\
\hline Importance of Politics & Survey & 442 & 5.583 & 2.746 & 0 & 10 \\
\hline Interest in Politics & Survey & 448 & 5.439 & 3.270 & 0 & 10 \\
\hline Political Efficacy & Survey & 333 & 41.420 & 16.36 & 0 & 90 \\
\hline Policy & Survey & 420 & 0 & 1 & -3.35 & 2.24 \\
\hline Lifestyle & Survey & 420 & 0 & 1 & -2.58 & 2.52 \\
\hline Career & Survey & 420 & 0 & 1 & -2.76 & 2.30 \\
\hline Science & Survey & 420 & 0 & 1 & -2.93 & 2.41 \\
\hline
\end{tabular}

Note : Survey refers to the CEU Survey, carried out in 2007 
Table 2: Determinants of Political Efficacy

\begin{tabular}{|c|c|c|c|c|c|c|}
\hline \multirow{2}{*}{$\begin{array}{l}\text { Political Opportunity } \\
\text { Structure }\end{array}$} & \multirow[b]{2}{*}{ Polity } & \multirow{2}{*}{$\begin{array}{l}(1) \\
1.12^{\mathrm{a}} \\
(4.64)\end{array}$} & \multirow{2}{*}{$\begin{array}{l}(2) \\
1.078^{\mathrm{a}} \\
(4.58)\end{array}$} & \multirow[t]{2}{*}{ (3) } & \multirow[t]{2}{*}{ (4) } & \multirow{2}{*}{$\begin{array}{l}(5) \\
1.106^{\mathrm{a}} \\
(4.41) \\
\end{array}$} \\
\hline & & & & & & \\
\hline & $\begin{array}{l}\text { FH Civil } \\
\text { Liberties }\end{array}$ & & & & $\begin{array}{l}-2.738^{\mathrm{a}} \\
(3.63)\end{array}$ & \\
\hline & $\begin{array}{l}\text { FH Political } \\
\text { Rights }\end{array}$ & & & $\begin{array}{l}-2.455^{\mathrm{a}} \\
(4.05)\end{array}$ & & \\
\hline \multirow[t]{2}{*}{ Reform -oriented } & Factor - Policy & $\begin{array}{l}3.05^{\mathrm{a}} \\
(2.88) \\
\end{array}$ & $\begin{array}{l}2.589^{b} \\
(2.43) \\
\end{array}$ & $\begin{array}{l}2.656^{\mathrm{b}} \\
(2.47) \\
\end{array}$ & $\begin{array}{l}2.688^{b} \\
(2.47)\end{array}$ & \\
\hline & $\begin{array}{l}\text { Contribute to } \\
\text { Societal Change }\end{array}$ & & & & & $\begin{array}{l}1.593^{\mathrm{a}} \\
(3.17)\end{array}$ \\
\hline \multirow[t]{2}{*}{ Career-oriented } & Factor - Career & $\begin{array}{l}2.58^{b} \\
(2.62)\end{array}$ & $\begin{array}{l}2.225^{\mathrm{b}} \\
(2.29)\end{array}$ & $\begin{array}{l}2.303^{b} \\
(2.33)\end{array}$ & $\begin{array}{l}2.364^{b} \\
(2.34)\end{array}$ & \\
\hline & Expected Income & & & & & $\begin{array}{l}1.037^{b} \\
(2.19)\end{array}$ \\
\hline \multicolumn{2}{|c|}{ Disciplinary Culture: Lifestyle } & $\begin{array}{l}1.15 \\
(1.07)\end{array}$ & $\begin{array}{l}0.695 \\
(0.66)\end{array}$ & $\begin{array}{l}0.367 \\
(0.34)\end{array}$ & $\begin{array}{l}0.415 \\
(0.38)\end{array}$ & \\
\hline \multicolumn{2}{|c|}{ Disciplinary Culture: Science } & $\begin{array}{l}0.09 \\
(0.10) \\
\end{array}$ & $\begin{array}{l}-0.239 \\
(0.26) \\
\end{array}$ & $\begin{array}{l}-0.18 \\
(0.19) \\
\end{array}$ & $\begin{array}{l}-0.205 \\
(0.21) \\
\end{array}$ & \\
\hline \multirow[t]{2}{*}{ Political Awareness } & Interest in Politics & $\begin{array}{l}0.90 \mathrm{a} \\
(3.07)\end{array}$ & & & & \\
\hline & $\begin{array}{l}\text { Importance of } \\
\text { Politics }\end{array}$ & & $\begin{array}{l}1.652^{\mathrm{a}} \\
(4.37)\end{array}$ & $\begin{array}{l}1.599^{\mathrm{a}} \\
(4.04)\end{array}$ & $\begin{array}{l}1.621^{\mathrm{a}} \\
(4.07)\end{array}$ & $\begin{array}{l}1.544^{\mathrm{a}} \\
(4.32)\end{array}$ \\
\hline \multicolumn{2}{|l|}{ Age } & $\begin{array}{l}-0.19 \\
(0.61) \\
\end{array}$ & $\begin{array}{l}-0.198 \\
(0.63) \\
\end{array}$ & $\begin{array}{l}-0.205 \\
(0.69) \\
\end{array}$ & $\begin{array}{l}-0.159 \\
(0.53) \\
\end{array}$ & $\begin{array}{l}-0.215 \\
(0.74) \\
\end{array}$ \\
\hline \multicolumn{2}{|l|}{ Gender } & $\begin{array}{l}0.35 \\
(0.19)\end{array}$ & $\begin{array}{l}0.907 \\
(0.49)\end{array}$ & $\begin{array}{l}1.943 \\
(1.04)\end{array}$ & $\begin{array}{l}2.009 \\
(1.07)\end{array}$ & $\begin{array}{l}0.631 \\
(0.36)\end{array}$ \\
\hline \multicolumn{2}{|l|}{ R-squared } & 0.17 & 0.20 & 0.19 & 0.18 & 0.20 \\
\hline \multicolumn{2}{|l|}{ Observations } & 286 & 281 & 282 & 282 & 293 \\
\hline
\end{tabular}

Absolute value of $\mathrm{t}$ statistics in parentheses; reported $\mathrm{t}$-statistics are calculated with robust standard errors. The tables report significance level for two-tailed tests.

$\mathrm{c}$ indicates significance at $10 \%$; b indicates significance at $5 \%$, a indicates significance at $1 \%$ 
Table 3: Determinants of Political Efficacy - Historical Legacy

\begin{tabular}{llc}
\hline & $(1)$ & $(2)$ \\
\hline $\begin{array}{l}\text { Political Opportunity Structure } \\
\text { Polity average) }\end{array}$ & & $1.064 \mathrm{a}$ \\
\hline Socialism & $-7.762^{\mathrm{a}}$ & $-6.84^{\mathrm{a}}$ \\
\hline Disciplinary Culture: Reform & $2.65)$ & $(3.15)$ \\
\hline Disciplinary Culture: Career & $(2.72)$ & $2.570^{\mathrm{a}}$ \\
& $2.409^{\mathrm{b}}$ & $2.829^{\mathrm{a}}$ \\
\hline Disciplinary Culture: Lifestyle & $(2.46)$ & $(2.87)$ \\
\hline Disciplinary Culture: Science & 0.6533 & 1.030 \\
& $(0.57)$ & $(0.95)$ \\
\hline Political Awareness: & 0.611 & 0.360 \\
Interest in Politics & $(0.65)$ & $(0.39)$ \\
\hline Age & $0.923^{\mathrm{a}}$ & $0.896^{\mathrm{a}}$ \\
& $(3.10)$ & $(3.11)$ \\
\hline Gender & -0.088 & -0.291 \\
& $(0.28)$ & $(0.95)$ \\
\hline R-squared & 2.795 & 1.154 \\
& $(1.49)$ & $(0.64)$ \\
Observations & 0.13 & 0.20 \\
\hline
\end{tabular}

Absolute value of t statistics in parentheses; reported t-statistics are calculated with robust standard errors. The tables report significance level for two-tailed tests.

c indicates significance at 10\%; b indicates significance at 5\%, a indicates significance at $1 \%$ 